\title{
Rhodium particles supported by thin vanadia films as model systems for catalysis: An electron microscopy study
}

\author{
S. Penner ${ }^{\mathrm{a}}$, D. Wang ${ }^{\mathrm{b}}$, R. Schlögl ${ }^{\mathrm{b}}$, K. Hayek ${ }^{\mathrm{a}, *}$ \\ ${ }^{a}$ Institut für Physikalische Chemie, Universität Innsbruck, Innrain 52a, A-6020 Innsbruck, Austria \\ ${ }^{\mathrm{b}}$ Fritz-Haber-Institut der Max-Planck-Gesellschaft, Faradayweg, 4-6, D-14195 Berlin, Germany
}

\begin{abstract}
Well-shaped $\mathrm{Rh}$ particles grown epitaxially on $\mathrm{NaCl}$ surfaces were coated with a $25 \mathrm{~nm}$ layer of crystalline vanadium oxide by reactive deposition in $10^{-4}$ mbar oxygen. The $\mathrm{Rh} / \mathrm{VO}_{\mathrm{x}}$ film was subjected to consecutive heat treatments in 1 bar oxygen and in 1 bar hydrogen up to $673 \mathrm{~K}$. The structural and morphological changes were monitored by (high-resolution) transmission electron microscopy, selected area electron diffraction and electron energy-loss spectroscopy and compared to the alterations of a bare vanadium oxide film treated under equal conditions. The stoichiometry and structure of the $\mathrm{VO}_{\mathrm{x}}$ support depend on the temperature of the $\mathrm{NaCl}$ template and on the deposition rate. Low deposition rates and high substrate temperatures favour the generation of a pure $\mathrm{V}_{2} \mathrm{O}_{3}$ phase, with both $\mathrm{V}_{2} \mathrm{O}_{3}$ and the Rh particles in epitaxial relation to $\mathrm{NaCl}(001)$.

A treatment in 1 bar $\mathrm{O}_{2}$ between 300 and $573 \mathrm{~K}$ converts the supporting oxide into mixed $\mathrm{V}_{2} \mathrm{O}_{3}, \mathrm{VO}_{2}$ and $\mathrm{V}_{2} \mathrm{O}_{5}$ phases. Oxidation at 673 $\mathrm{K}$ induces a complete reconstruction into a single $\mathrm{V}_{2} \mathrm{O}_{5}$ phase, while an oxygen treatment at $723 \mathrm{~K}$ transforms also the Rh particles into $(\beta) \mathrm{Rh}_{2} \mathrm{O}_{3}$. Reduction of the bare $\mathrm{V}_{2} \mathrm{O}_{5}$ film in 1 bar hydrogen yields cubic VO at $673 \mathrm{~K}$, but reduction of the $\mathrm{Rh} / \mathrm{V}_{2} \mathrm{O}_{5}$ film leads to $\mathrm{VO}$ formation already at $473 \mathrm{~K}$. Finally, a reduction of vanadia-supported $\mathrm{Rh}$ particles at and above $573 \mathrm{~K}$ results in the formation of $\mathrm{Rh} / \mathrm{V}$ alloy structures.
\end{abstract}

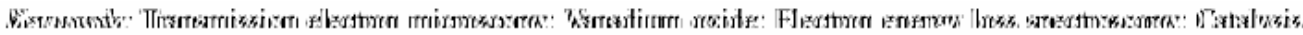

\section{Introduction}

Oxide-supported rhodium particles have found numerous applications in heterogeneous catalysis. Vanadia-promoted rhodium is a very efficient catalyst for redox reactions, and vanadium oxide is known to promote the $\mathrm{CO}$ hydrogenation towards alcohols and other oxygenates $[1,2]$. If the $\mathrm{Rh} /$ vanadia system is transformed into a highly reduced state, strong metal-support interaction occurs [3] and the selectivity to ethanol may be close to $100 \%$ [4].

The synergism of rhodium and vanadium oxide to steer a catalytic reaction has also been observed on so-called

\footnotetext{
* Corresponding author. Tel.: +43 512507 5062; fax: +43 5125072925 . E-mail address: konrad.hayek@uibk.ac.at (K. Hayek).
}

"inverse" supported catalysts. Submonolayers of vanadia on a $\mathrm{Rh}$ surface also promote the $\mathrm{CO}$ hydrogenation and change the selectivity from methane to longer hydrocarbons $[5,6]$. Some of the present authors could recently show that a reduction of the vanadia overlayers at elevated temperature has a crucial influence on both the surface composition and the catalytic activity of a polycrystalline Rh surface [7]. A reduction at $773 \mathrm{~K}$ and above converts the $\mathrm{VO}_{\mathrm{x}}$ submonolayers into a chemically and thermally stable subsurface $\mathrm{Rh} /$ $\mathrm{V}$ alloy with characteristic catalytic properties $[8,9]$.

While the structural and chemical changes upon hightemperature reduction can be conveniently studied on "inverse" model systems by using Surface Science techniques [10], information about the surface stoichiometry and microstructure of industrial supported $\mathrm{Rh} /$ vanadia catalysts is not easily obtained. (Ex situ) electron micro- 
scopy and diffraction are among the most useful techniques, but for high-resolution imaging and microdiffraction a defined crystallographic orientation of the noble metal particles (which should not be too small in size) is almost a necessity. This can be accomplished with a model system of epitaxially grown $\mathrm{Rh}$ particles in contact with a vanadia promoter or support. These "thin film model catalysts" and their advantages in studies of microstructural changes have been described previously [11]. If the thickness of the supporting film is kept below about $25 \mathrm{~nm}$, they are particularly suited for characterization by high-resolution electron microscopy and selected area electron diffraction. Due to the regular polyhedral habit of the Rh particles they provide a definite initial state, allowing an easier detection and a better understanding of the alterations during the subsequent oxidation or reduction treatment. In the present investigation we follow the structural changes of the $\mathrm{Rh}$ particles and of a supporting vanadia film as a function of treatments in oxygen and hydrogen up to $673 \mathrm{~K}$ and attempt a correlation to the results obtained on the "inverse" counterpart, i.e., on the vanadia covered rhodium foil.

\section{Experimental details}

Nanocrystalline Rh particles were prepared by electronbeam deposition of the metal on vacuum-cleaved $\mathrm{NaCl}$ surfaces at a base pressure of $10^{-4} \mathrm{~Pa}$ and a substrate temperature of $623 \mathrm{~K}$. They were covered by a supporting layer of vanadium oxide (20-25 nm thick), obtained by reactive deposition of $\mathrm{V}$ metal in $10^{-2} \mathrm{~Pa}$ oxygen, again at $623 \mathrm{~K}$. For comparison, a pure vanadia film of the same thickness was also prepared and investigated in parallel. After dissolving the $\mathrm{NaCl}$ in distilled water the films were mounted on gold grids for electron microscopy observations.

The pure vanadia film and the $\mathrm{Rh} / \mathrm{VO}_{\mathrm{x}}$ film were subjected to oxidative ( 1 bar $\mathrm{O}_{2}$ for $1 \mathrm{~h}$ ) and reductive (1 bar $\mathrm{H}_{2}$ for $1 \mathrm{~h}$ ) treatments in the temperature range between 373 and $673 \mathrm{~K}$, either in a flow system or in a circulating batch reactor. The resulting changes in structure and morphology were followed by high-resolution transmission electron microscopy (HRTEM), selected area electron diffraction (SAED) and electron energy loss spectroscopy (EELS). The electron micrographs were taken with a ZEISS EM 10C and with a Philips CM 200 microscope equipped with a field emission gun and a Gatan imaging filter.

\section{Results and discussion}

\subsection{The $V O_{x}$ film, as grown and upon oxidation to $673 \mathrm{~K}$}

Fig. 1a shows a $\mathrm{VO}_{\mathrm{x}}$ film on $\mathrm{NaCl}(001)$ deposited at room temperature (a), in comparison to a film deposited at $623 \mathrm{~K}$ (b), both at the same (low) deposition rate of $0.8 \AA$ vanadium $/ \mathrm{s}$. Whereas the former consists of very small grains, the latter is composed of regularly shaped
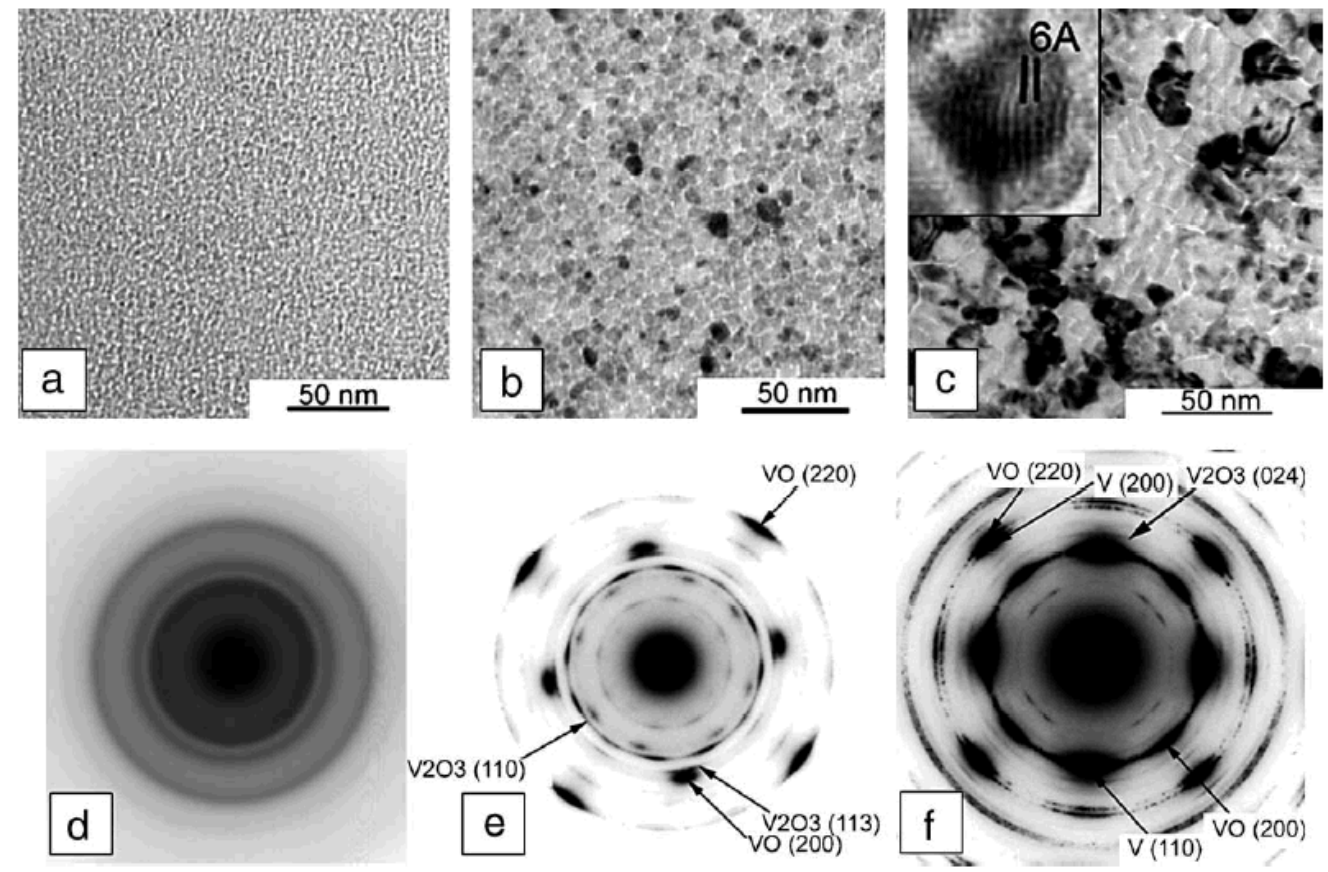

Fig. 1. Bare $\mathrm{VO}_{\mathrm{x}}$ films deposited at room temperature (a) and at $623 \mathrm{~K}$ (b, c). Deposition rate: $0.8 \AA \mathrm{V} / \mathrm{s}$ (a, b) and $12 \AA \mathrm{V} / \mathrm{s}$ (c). The insert in (c) shows Moiré patterns due to overlapping VO and V lattices. The corresponding SAED patterns are shown in (d), (e) and (f). 
crystallites (average grain size about $6 \mathrm{~nm}$ ). Their difference is also revealed in the SAED patterns. The pattern arising from the low-temperature film (Fig. 1d) contains broad reflections and is typical for an almost amorphous structure. In contrast, the diffraction pattern of the hightemperature film (Fig. 1e) reveals a crystalline phase in orientational relation with the substrate. The broadening of the diffraction spots indicates that the grains are only partially ordered. Table 1 indicates that most of the reflections can be unambiguously assigned to rhombohedral $\mathrm{V}_{2} \mathrm{O}_{3}$ while the rest may be attributed to $\mathrm{V}_{2} \mathrm{O}_{3}$ but also to cubic VO which cannot be fully excluded. As seen in Fig. 1b, the electron micrographs of $\mathrm{V}_{2} \mathrm{O}_{3}$ films obtained at high temperature and low deposition rate are dominated by Bragg contrast. A (partially ordered) $\mathrm{V}_{2} \mathrm{O}_{3}$ phase is not only revealed by SAED (Fig. 1e) but also by HR-imaging. Fig. 2 shows several $\mathrm{V}_{2} \mathrm{O}_{3}$ grains in high resolution. Lattice fringes of 2.46 and $2.03 \AA$ can be distinguished arising from $\mathrm{V}_{2} \mathrm{O}_{3}(110)\left[d_{\text {theor }}(110)=2.45 \AA\right]$ and from $\mathrm{V}_{2} \mathrm{O}_{3}(202)\left[d_{\text {theor }}(202)=2.04 \AA\right]$, respectively. These two lattice spacings correspond to intense reflections in the SAED pattern.

Fig. 1c shows a $\mathrm{VO}_{x}$ film deposited a high rate $(12 \AA$ $\mathrm{V} / \mathrm{s}$ ) at a substrate temperature of $623 \mathrm{~K}$. Larger elongated grains (15-30 nm in size) are now observed. In the SAED pattern (Fig. 1f) reflections arising from fcc $\mathrm{VO}$ and from bcc $\mathrm{V}$ metal are detected besides those from $\mathrm{V}_{2} \mathrm{O}_{3}$, all in epitaxial relation to $\mathrm{NaCl}(001)$ (Table 1). Some weak reflections could not be assigned and may possibly arise from other substoichiometric phases. The VO grains grow mainly in their [001] zone axis, although weak reflections arising from a [011] axis (VO (111) and (311)) are also detected. Also the $\mathrm{V}$ particles exhibit both zone axes. The three components $\mathrm{V}_{2} \mathrm{O}_{3}$, $\mathrm{VO}$ and $\mathrm{V}$ metal are well-oriented with respect to each other. The composition and the crystallographic relations can also be deduced from a

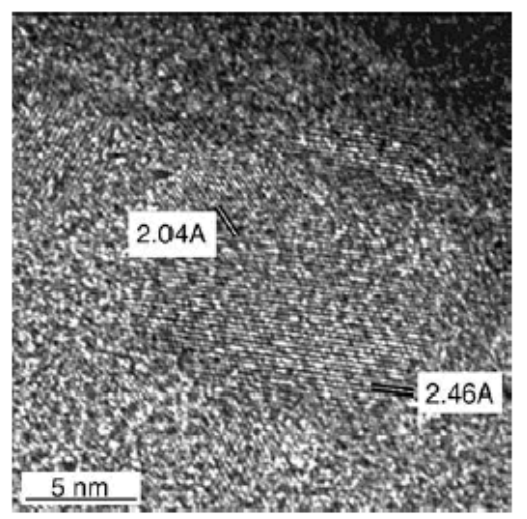

Fig. 2. High resolution detail of the $\mathrm{V}_{2} \mathrm{O}_{3}$ film shown in Fig. 1 (b).

number of Moiré patterns appearing in the "darker" domains, e.g., the fringes of about $6 \AA$ shown in the insert of Fig. 1c arise from overlapping parallel VO (200) and V (200) spacings. They underline the ordered growth of $\mathrm{V}$ and $\mathrm{VO}$ in the relations $\mathrm{VO}[011] / \mathrm{NaCl}[011]$ and $\mathrm{VO}(001) / /$ $\mathrm{NaCl}(001), \mathrm{V}[011] / \mathrm{NaCl}[011]$ and $\mathrm{V}(001) / \mathrm{NaCl}(001)$. Moiré patterns are only observed on the dark patches (Fig. 1c), thus suggesting that the darker domains correspond to V-rich areas.

Upon exposure to oxygen at $473 \mathrm{~K}$ for $1 \mathrm{~h}$ the electron image and diffraction are still characteristic of $\mathrm{V}_{2} \mathrm{O}_{3}$, and no considerable changes are observed compared to the asgrown state. Upon oxidation at $573 \mathrm{~K}$ the film starts to recrystallize and it undergoes a transformation into large elongated islands. The SAED patterns (not shown here) indicate the simultaneous presence of $\mathrm{V}_{2} \mathrm{O}_{3}, \mathrm{VO}_{2}$ and $\mathrm{V}_{2} \mathrm{O}_{5}$. Increasing the oxidation temperature to $673 \mathrm{~K}$ leads to further significant changes of the microstructure. The lowmagnification micrograph (Fig. 3a) shows oblong and sharp-edged crystals characteristic of $\mathrm{V}_{2} \mathrm{O}_{5}$. The SAED pattern (Fig. 3b and Table 1) matches the literature-reported

Table 1

Interplanar distances $d_{\text {hkl }}[\hat{\mathrm{A}}]$ measured on $\mathrm{VO}_{x}$ films deposited at $623 \mathrm{~K}$ at different rates, and possible correlation to rhombohedral $\mathrm{V}_{2} \mathrm{O}_{3}$, orthorhombic $\mathrm{V}_{2} \mathrm{O}_{5}$, fcc VO and bec V metal (n.a... . not assigned)

\begin{tabular}{|c|c|c|c|c|c|c|c|c|}
\hline \multicolumn{3}{|c|}{$\mathrm{V}$ deposition rate: $0.8 \AA \mathrm{A} \mathrm{V} / \mathrm{s}$ Substrate temperature $623 \mathrm{~K}$} & \multicolumn{3}{|c|}{ V deposition rate: $12 \AA / \mathrm{A} / \mathrm{s}$ Substrate temperature $623 \mathrm{~K}$} & \multicolumn{3}{|c|}{ After oxidation $673 \mathrm{~K}, 1 \mathrm{~h}$} \\
\hline \multicolumn{3}{|c|}{ Assignment } & \multicolumn{3}{|c|}{ Assignment } & \multicolumn{3}{|c|}{ Assignment } \\
\hline$d(\mathrm{hkl})_{\exp }$ & Lattice plane & $d(\mathrm{hkl})_{\text {thoor }}$ & $d(\mathrm{hkl})_{\exp }$ & Lattice plane & $d(\mathrm{hkl})_{\text {thoor }}$ & $d(\mathrm{hkl})_{\exp }$ & Lattice plane & $d(\mathrm{hkl})_{\text {thoor }}$ \\
\hline 3.63 & $\mathrm{~V}_{2} \mathrm{O}_{3}(012)$ & {$[3.65]$} & 3.04 & n.a. & & 5.75 & $\mathrm{~V}_{2} \mathrm{O}_{5}(200)$ & {$[5.74]$} \\
\hline 2.71 & $\mathrm{~V}_{2} \mathrm{O}_{3}(104)$ & {$[2.71]$} & 2.36 & VO (111) & {$[2.35]$} & 4.41 & $\mathrm{~V}_{2} \mathrm{O}_{5}(010)$ & {$[4.36]$} \\
\hline 2.45 & $\mathrm{~V}_{2} \mathrm{O}_{3}(110)$ & {$[2.47]$} & 2.13 & $\mathrm{~V}(110)$ & {$[2.14]$} & 4.07 & $\mathrm{~V}_{2} \mathrm{O}_{5}(110)$ & {$[4.07]$} \\
\hline 2.17 & $\mathrm{~V}_{2} \mathrm{O}_{3}(113)$ & [2.19] & 2.02 & VO $(200)$ & {$[2.03]$} & 3.39 & $\mathrm{~V}_{2} \mathrm{O}_{5}(101)$ & [3.39] \\
\hline \multirow[t]{2}{*}{2.04} & $\mathrm{~V}_{2} \mathrm{O}_{3}(202)$ & {$[2.05]$} & 1.87 & $\mathrm{~V}_{2} \mathrm{O}_{3}(024)$ & {$[1.83]$} & 2.91 & $\mathrm{~V}_{2} \mathrm{O}_{5}(400)$ & {$[2.87]$} \\
\hline & VO $(200)$ & {$[2.03]$} & & & & & & \\
\hline 1.83 & $\mathrm{~V}_{2} \mathrm{O}_{3}(024)$ & {$[1.83]$} & 1.69 & $\mathrm{~V}_{2} \mathrm{O}_{3}(116)$ & {$[1.70]$} & 2.73 & $\mathrm{~V}_{2} \mathrm{O}_{5}(011)$ & {$[2.75]$} \\
\hline 1.69 & $\mathrm{~V}_{2} \mathrm{O}_{3}(116)$ & {$[1.70]$} & 1.53 & V (200) & {$[1.51]$} & 2.61 & $\mathrm{~V}_{2} \mathrm{O}_{5}(301)$ & {$[2.60]$} \\
\hline 1.57 & $\mathrm{~V}_{2} \mathrm{O}_{3}(122)$ & {$[1.60]$} & 1.47 & VO $(220)$ & {$[1,44]$} & 2.46 & $\mathrm{~V}_{2} \mathrm{O}_{5}(211)$ & {$[2.48]$} \\
\hline \multirow[t]{2}{*}{1.47} & $\mathrm{~V}_{2} \mathrm{O}_{3}(214)$ & {$[1.47]$} & 1.37 & n.a. & & 2.35 & $\mathrm{~V}_{2} \mathrm{O}_{5}(410)$ & {$[2.39]$} \\
\hline & VO $(200)$ & {$[1.44]$} & 1.30 & n.a. & & 2.16 & $\mathrm{~V}_{2} \mathrm{O}_{5}(020)$ & {$[2.18]$} \\
\hline \multirow[t]{3}{*}{1.42} & $\mathrm{~V}_{2} \mathrm{O}_{3}(310)$ & {$[1.43]$} & 1.25 & $\mathrm{~V}(211)$ & {$[1.24]$} & 1.99 & $\mathrm{~V}_{2} \mathrm{O}_{5}(411)$ & {$[1.98]$} \\
\hline & & & 1.23 & VO (311) & {$[1.22]$} & & & \\
\hline & & & 1.07 & V (220) & {$[1,07]$} & & & \\
\hline
\end{tabular}



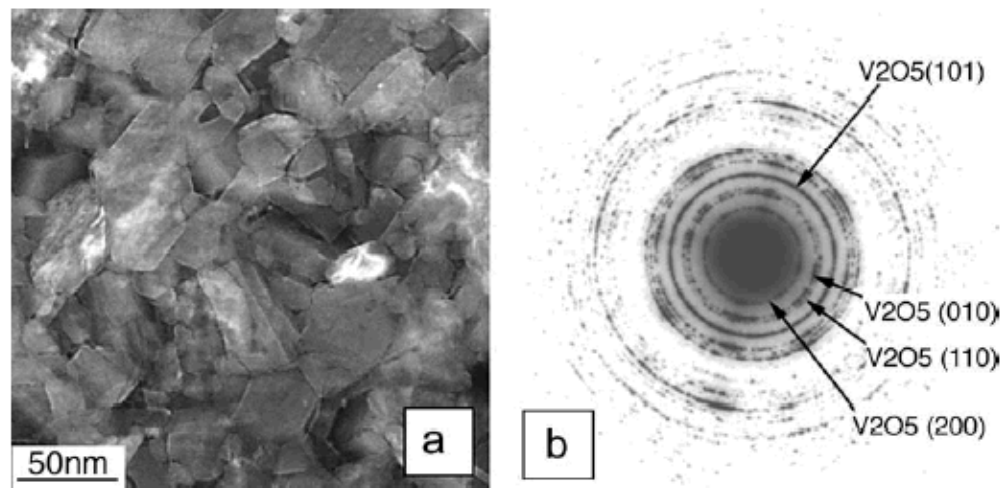

Fig. 3. Bare $\mathrm{V}_{2} \mathrm{O}_{3}$ film after oxidation at $673 \mathrm{~K}$ in 1 bar oxygen (a) and corresponding SAED pattern (b).

$\mathrm{X}$-ray data of $\mathrm{V}_{2} \mathrm{O}_{5}$ [12]. Partial ordering with respect to the former $\mathrm{NaCl}$ substrate is still observed. In the HRTEM images (Fig. 4) lattice fringes of about $3.4 \AA$ (Fig. 4a) and $4.1 \AA$ (Fig. 4b) are observed, corresponding to $\mathrm{V}_{2} \mathrm{O}_{5}(101)$ $\left[d_{\text {theor }}(101)=3.39 \AA\right]$ and $\mathrm{V}_{2} \mathrm{O}_{5}(110)\left[d_{\text {theor }}(110)=4.07 \AA\right]$, respectively.

\subsection{The $\mathrm{VO}_{x}$ film after reduction up to $673 \mathrm{~K}$}

After oxidation to $\mathrm{V}_{2} \mathrm{O}_{5}$ at $673 \mathrm{~K}$, a stepwise reduction was performed at increasing temperature, with the aim to obtain one uniform $\mathrm{VO}_{x}(x<2.5)$ phase. After reduction at $473 \mathrm{~K}$ and above the grain structure of $\mathrm{V}_{2} \mathrm{O}_{5}$ still persists in electron image and diffraction, but after reduction at $673 \mathrm{~K}$ the film attains a new "porous" structure in which the former vanadia grains can still be recognized (Fig. 5a). The diffraction pattern indicates cubic VO (Fig. 5b), and HRTEM reveals widespread lattice fringes of VO (2.04 $2.07 \AA, d_{200}(\mathrm{VO})=2.03 \AA$ ) (Fig. 6).

Additional information about the electronic structure of the newly formed VO-phase was obtained by EELS. It is known that the ratio of the $\mathrm{V} L_{3} / L_{2}$ peak intensities increases with decreasing oxidation state of vanadium and that the intensity of the $\mathrm{O}$ pre-edge peak decreases with decreasing valence state of vanadium $[13,14]$. Hence it is reasonable to use these two features to characterise the oxidation state. Fig. 7 shows a set of high energy-loss spectra taken after several oxidation and reduction steps in comparison with the spectrum of the untreated $\mathrm{V}_{2} \mathrm{O}_{3}$ film. Each spectrum was first calibrated by the corresponding zero-loss spectrum, and then the background was subtracted and plural scattering was removed [15]. The spectra were compared with the EELS spectra of different $\mathrm{V}$-oxides reported by $\mathrm{Lin}$ et al. [13]. The spectrum of the untreated sample $\left(\mathrm{V}_{2} \mathrm{O}_{3}\right)$ and that obtained after oxidation at $673 \mathrm{~K}\left(\mathrm{~V}_{2} \mathrm{O}_{5}\right)$ agree with the reported spectra with respect to the $\mathrm{V} L$-edges and the near-edge structure of the $\mathrm{O} K$-edge. In contrast, EELS spectra collected after oxidation at $573 \mathrm{~K}$ are consistent with the presence of a mixture of V-oxides. A shift of the V $L$-edges to higher energy losses, a change in the relative ratio of the $\mathrm{V} L_{3} / L_{2}$ edges and a distinct change of the $\mathrm{O} K$ edge point to the presence of higheroxidized vanadium states.

The change in the oxidation state of $\mathrm{V}$ after reduction at $673 \mathrm{~K}$ is confirmed by a shift of the $\mathrm{V} L$-edges to lower energy loss compared to the sample oxidized at $673 \mathrm{~K}$ and by a change in their relative intensities. In addition, the $\mathrm{O} K$ edge has changed its structure back to that expected for lower oxidized states.
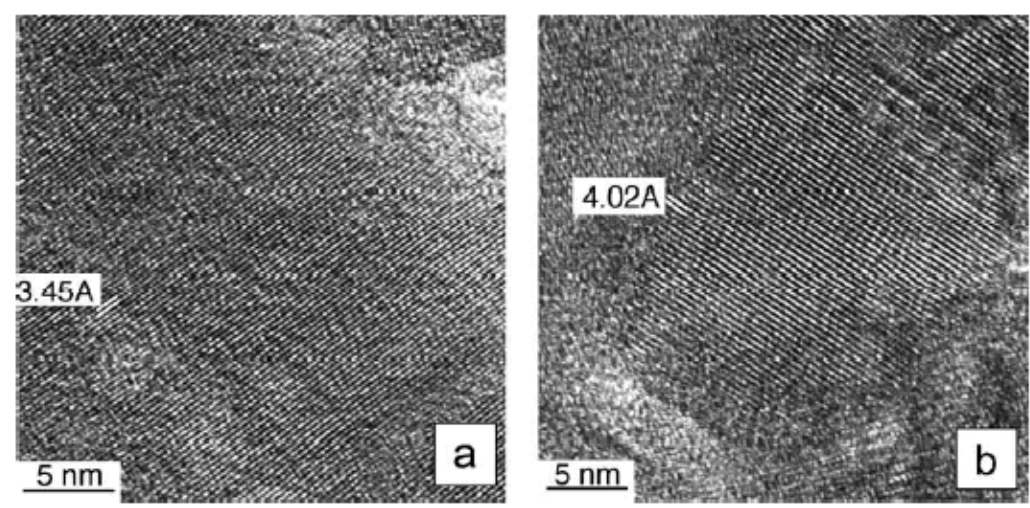

Fig. 4. HRTEM images of $\mathrm{V}_{2} \mathrm{O}_{5}$ grains exhibiting (101) (a) and (110) (b) lattice fringes. 

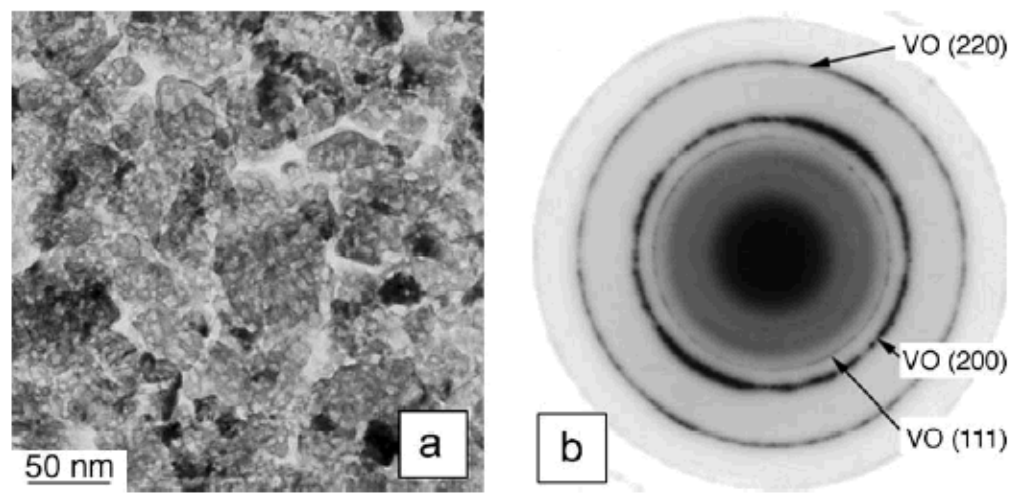

Fig. 5. $\mathrm{V}_{2} \mathrm{O}_{3}$ film after oxidation at $673 \mathrm{~K}$ and subsequent reduction at $673 \mathrm{~K}$ in 1 bar hydrogen (a), and corresponding SAED pattern (b).

\subsection{The $R h / V O_{x}$ film as grown and after oxidation up to $723 \mathrm{~K}$}

Fig. 8a shows as-deposited Rh particles supported by $\mathrm{V}_{2} \mathrm{O}_{3}$ (nominal thickness of the deposited $\mathrm{Rh}$ film $1.8 \mathrm{~nm}$, mean particle size $12 \mathrm{~nm}$, thickness of the $\mathrm{VO}_{x}$ supporting layer $25 \mathrm{~nm}$ ). The $\mathrm{Rh}$ particles exhibit square, rectangular and triangular shapes and can be well distinguished from the $\mathrm{V}_{2} \mathrm{O}_{3}$ support. Their three-dimensional habit was determined earlier by HREM and weak-beam dark field imaging to be mainly half-octahedral and half-tetrahedral [11]. The electron diffraction (Fig. 8b and Table 2) is a superposition of the $\mathrm{V}_{2} \mathrm{O}_{3}$ and the $\mathrm{Rh}$ patterns. It indicates perfect epitaxial growth of the Rh particles and a partial ordering of the $\mathrm{V}_{2} \mathrm{O}_{3}$ grains on the former $\mathrm{NaCl}(001)$ template.

After oxidation at $473 \mathrm{~K}$ the microstructure of the $\mathrm{Rh} /$ vanadia film is unchanged compared to the as-grown state and the SAED pattern shows well-oriented $\mathrm{Rh}$ particles and a uniform $\mathrm{V}_{2} \mathrm{O}_{3}$ phase. The absence of extra reflections shows that no interaction between $\mathrm{Rh}$ and $\mathrm{V}_{2} \mathrm{O}_{3}$ has taken place. Raising the oxidation temperature to $573 \mathrm{~K}$ causes a slight sintering of the $\mathrm{V}_{2} \mathrm{O}_{3}$ support and a

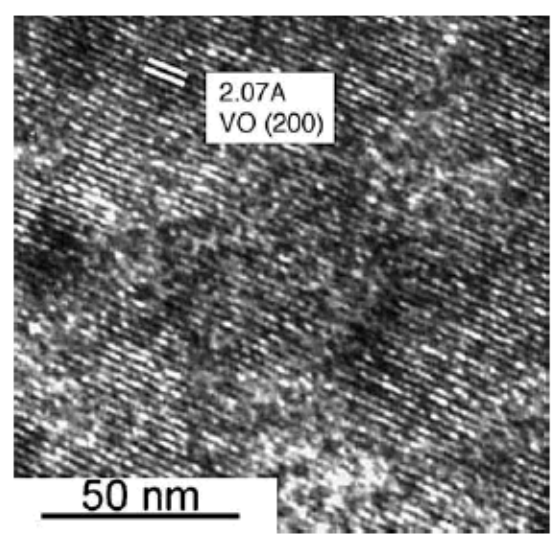

Fig. 6. VO (200) lattice fringes observed after oxidation at $673 \mathrm{~K}$ followed by reduction in 1 bar hydrogen at $673 \mathrm{~K}$. closing of the grain boundaries (Fig. 9a). As expected from the behaviour of the corresponding $\mathrm{Rh} / \mathrm{Al}_{2} \mathrm{O}_{3}$ system studied previously [16], the Rh particles keep their regular outlines and their shape remains almost unaffected. First signs of orientational disorder are indicated by the appearance of $\mathrm{Rh}$ (111) reflections in the diffraction pattern (Fig. 9c). However, at the same time the support changes its composition, similarly as the bare $\mathrm{V}_{2} \mathrm{O}_{3}$ film. Additional reflections in the SAED pattern are attributable to monoclinic $\mathrm{VO}_{2}\left(d_{-111}\left(\mathrm{VO}_{2}\right)=3.31 \AA\right.$ and $d_{011}\left(\mathrm{VO}_{2}\right)=$ $3.20 \AA$, Table 2). The $\mathrm{VO}_{2}$ phase appears partially ordered in electron diffraction.

Similarly as observed on the bare vanadia film, a further increase of the oxidation temperature to $673 \mathrm{~K}$ results in the reconstruction into large $\mathrm{V}_{2} \mathrm{O}_{5}$ grains supporting the noble metal particles. The $\mathrm{Rh}$ particles are not affected by this transformation of the support and keep their rectangular and square outlines (Fig. 9b). The SAED pattern (Fig. 9d) and the $\mathrm{V}_{2} \mathrm{O}_{5}(200)$ lattice spacings observed at high resolution (5.74 $\AA$, insert in Fig. 9b) both reveal a uniform $\mathrm{V}_{2} \mathrm{O}_{5}$ phase.

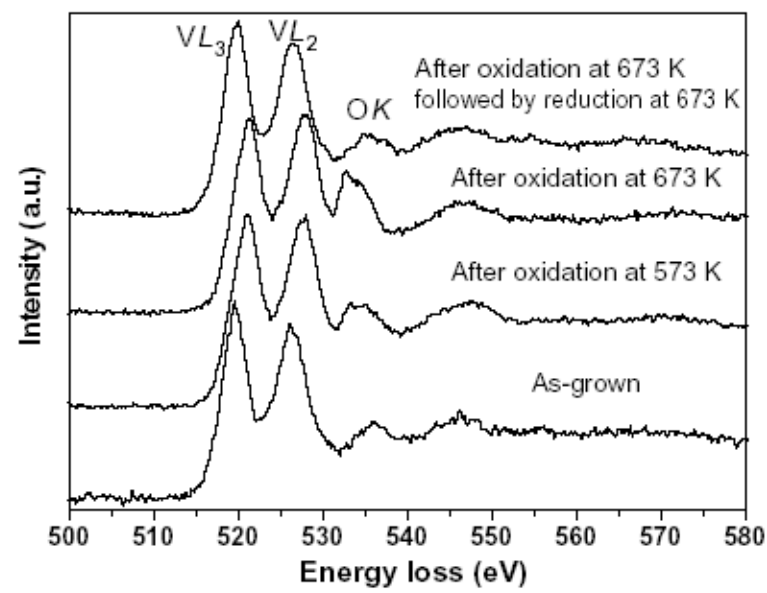

Fig. 7. EELS spectra of the bare $\mathrm{V}_{2} \mathrm{O}_{3}$ film after various oxidation and reduction steps. 

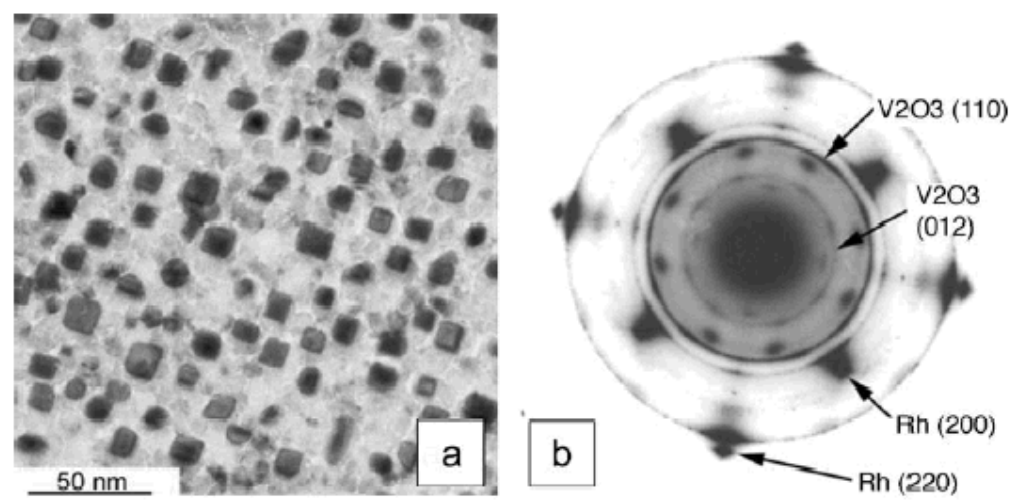

Fig. 8. As-grown $\mathrm{Rh} / \mathrm{V}_{2} \mathrm{O}_{3}$ film (a) and SAED pattern (b). Mean $\mathrm{Rh}$ particle size $12 \mathrm{~mm}$.

After oxidation at $723 \mathrm{~K}$ the appearance of the vanadia support is unchanged, but the $\mathrm{Rh}$ particles are now surrounded by a shell of $\beta-\mathrm{Rh}_{2} \mathrm{O}_{3}$, in analogy to the observations made by Rupprechter et al. [16] after oxidation of a corresponding $\mathrm{Rh} / \mathrm{Al}_{2} \mathrm{O}_{3}$ system at the same temperature (not shown here). In conclusion, the changes in the support during oxidation can be considered as independent of the presence of $\mathrm{Rh}$ particles and vice versa.

\subsection{The $\mathrm{Rh} / \mathrm{VO} \mathrm{O}_{x}$ film after reduction up to $673 \mathrm{~K}$}

Subsequent to the oxidation at $673 \mathrm{~K}$, a series of reduction treatments was performed on the $\mathrm{Rh} /$ vanadia system. A reduction below $473 \mathrm{~K}$ leaves the microstructure unchanged and the SAED pattern consists of rings from $\mathrm{V}_{2} \mathrm{O}_{5}$ and of broadened spots from fcc $\mathrm{Rh}$, revealing that most $\mathrm{Rh}$ particles are still in their [110] zone axis. However, a reduction at $473 \mathrm{~K}$ induces significant structural alterations particularly of the support (Fig. 10a). Although the shape of the former $\mathrm{V}_{2} \mathrm{O}_{5}$ grains is still recognized, the support appears porous, similar to the bare $\mathrm{VO}_{\mathrm{x}}$ film after reduction at $673 \mathrm{~K}$. The SAED pattern (Fig. 10d) reveals cubic VO. Obviously the $\mathrm{Rh}$ particles catalyze the reduction of $\mathrm{V}_{2} \mathrm{O}_{5}$ to lower oxidation states. The Rh particles keep their regular outlines, but appear to be enclosed by the reduced support (Fig. 10a).

A further reduction at $573 \mathrm{~K}$ does not change the appearance of the particles or the supporting oxide in the electron micrograph (Fig. 10b), but a number of new reflections appear in the diffraction pattern that may be attributed to alloy formation between rhodium and vanadium (Fig. 10e and Table 3). The entire pattern can be interpreted as a superposition arising from i) (001) oriented $\mathrm{Rh}$ particles, ii) a slightly ordered VO support, and iii) an orthorhombic $\mathrm{Rh}_{5} \mathrm{~V}_{3}$ phase in good epitaxial relation with the Rh particles.

Further raising the reduction temperature results in an apparent enlargement of the metal particles on the electron micrograph and to a loss of particle ordering (shown in Fig. $10 \mathrm{c}$ for $T_{\text {red }}=673 \mathrm{~K}$ ). At the same time a large number of partly new ring reflections appear in the diffraction

Table 2

Interplanar distances $d_{\mathrm{hkl}}[\hat{\mathrm{A}}]$ measured on $\mathrm{Rh} / \mathrm{VO}_{x}$ as-grown and after oxidation at 573 , and $673 \mathrm{~K}$ and possible correlation to rhombohedral $\mathrm{V}_{2} \mathrm{O}_{3}$, monoclinic $\mathrm{VO}_{2}$, orthorhombic $\mathrm{V}_{2} \mathrm{O}_{5}$ and fcc $\mathrm{Rh}$ (n......not assigned)

\begin{tabular}{|c|c|c|c|c|c|c|c|c|}
\hline \multicolumn{3}{|c|}{$\mathrm{Rh} / \mathrm{VO}_{x}$ as-grown } & \multicolumn{3}{|c|}{$\underline{\mathrm{Rh} / \mathrm{VO}_{x} \text { after oxidation at } 573 \mathrm{~K}}$} & \multicolumn{3}{|c|}{$\mathrm{Rh} / \mathrm{VO}_{x}$ after oxidation at $673 \mathrm{~K}$} \\
\hline \multicolumn{3}{|l|}{ Assignment } & \multicolumn{3}{|c|}{ Assignment } & \multicolumn{3}{|c|}{ Assignment } \\
\hline$d(\mathrm{hkl})_{\exp }$ & Lattice plane & $d(\mathrm{hkl})_{\text {theor }}$ & $d(\mathrm{hkl})_{\exp }$ & Lattice plane & $d(\mathrm{hkl})_{\text {theor }}$ & $d(\mathrm{hkl})_{\exp }$ & Lattice plane & $d(\mathrm{hkl})_{\text {theor }}$ \\
\hline 4.26 & n.a. & & 3.36 & $\mathrm{VO}_{2}(-111)$ & {$[3.31]$} & 5.73 & $\mathrm{~V}_{2} \mathrm{O}_{5}(200)$ & {$[5.74]$} \\
\hline 3.62 & $\mathrm{~V}_{2} \mathrm{O}_{3}(012)$ & {$[3.66]$} & 3.14 & $\mathrm{VO}_{2}(011)$ & {$[3.20]$} & 4.36 & $\mathrm{~V}_{2} \mathrm{O}_{5}(010)$ & {$[4.36]$} \\
\hline 2.74 & $\mathrm{~V}_{2} \mathrm{O}_{3}(104)$ & {$[2.71]$} & 2.44 & $\mathrm{~V}_{2} \mathrm{O}_{3}(110)$ & {$[2.48]$} & 3.38 & $\mathrm{~V}_{2} \mathrm{O}_{5}(101)$ & {$[3.39]$} \\
\hline 2.44 & $\mathrm{~V}_{2} \mathrm{O}_{3}(110)$ & {$[2.48]$} & 2.18 & $\mathrm{Rh}(111)$ & [2.19] & 2.88 & $\mathrm{~V}_{2} \mathrm{O}_{5}(400)$ & {$[2.87]$} \\
\hline 2.18 & $\mathrm{~V}_{2} \mathrm{O}_{3}(113)$ & {$[2.18]$} & 2.09 & $\mathrm{~V}_{2} \mathrm{O}_{3}(202)$ & {$[2.05]$} & 2.61 & $\mathrm{~V}_{2} \mathrm{O}_{5}(301)$ & {$[2.60]$} \\
\hline 2.05 & $\mathrm{~V}_{2} \mathrm{O}_{3}(202)$ & {$[2.05]$} & 1.89 & $\mathrm{Rh}(200)$ & {$[1.89]$} & 2.46 & $\mathrm{~V}_{2} \mathrm{O}_{5}(211)$ & [2.48] \\
\hline 1.89 & $\mathrm{Rh}(200)$ & {$[1.89]$} & 1.81 & $\mathrm{~V}_{2} \mathrm{O}_{3}(024)$ & {$[1.82]$} & 2.36 & $\mathrm{~V}_{2} \mathrm{O}_{5}(410)$ & [2.39] \\
\hline 1.79 & $\mathrm{~V}_{2} \mathrm{O}_{3}(024)$ & [1.83] & 1.63 & $\mathrm{VO}_{2}(211)$ & {$[1.65]$} & 2.17 & $\mathrm{Rh}(111)$ & {$[2.19]$} \\
\hline 1.68 & $\mathrm{~V}_{2} \mathrm{O}_{3}(116)$ & {$[1.70]$} & 1.41 & $\mathrm{~V}_{2} \mathrm{O}_{3}(300)$ & {$[1.43]$} & 1.89 & $\mathrm{Rh}(200)$ & [1.89] \\
\hline 1.47 & $\mathrm{~V}_{2} \mathrm{O}_{3}(214)$ & {$[1.47]$} & 1.34 & $\mathrm{Rh}(220)$ & {$[1.34]$} & 1.76 & $\mathrm{~V}_{2} \mathrm{O}_{5}(002)$ & {$[1.78]$} \\
\hline 1.43 & $\mathrm{~V}_{2} \mathrm{O}_{3}(300)$ & {$[1.43]$} & & & & 1.50 & $\mathrm{~V}_{2} \mathrm{O}_{5}(701)$ & {$[1.48]$} \\
\hline 1.34 & $\mathrm{Rh}(220)$ & {$[1.34]$} & & & & 1.34 & $\mathrm{Rh}(220)$ & {$[1.34]$} \\
\hline 1.24 & $\mathrm{~V}_{2} \mathrm{O}_{3}(220)$ & {$[1.24]$} & & & & & & \\
\hline
\end{tabular}


Thin Solid Films 484 (2005) p 10- 17
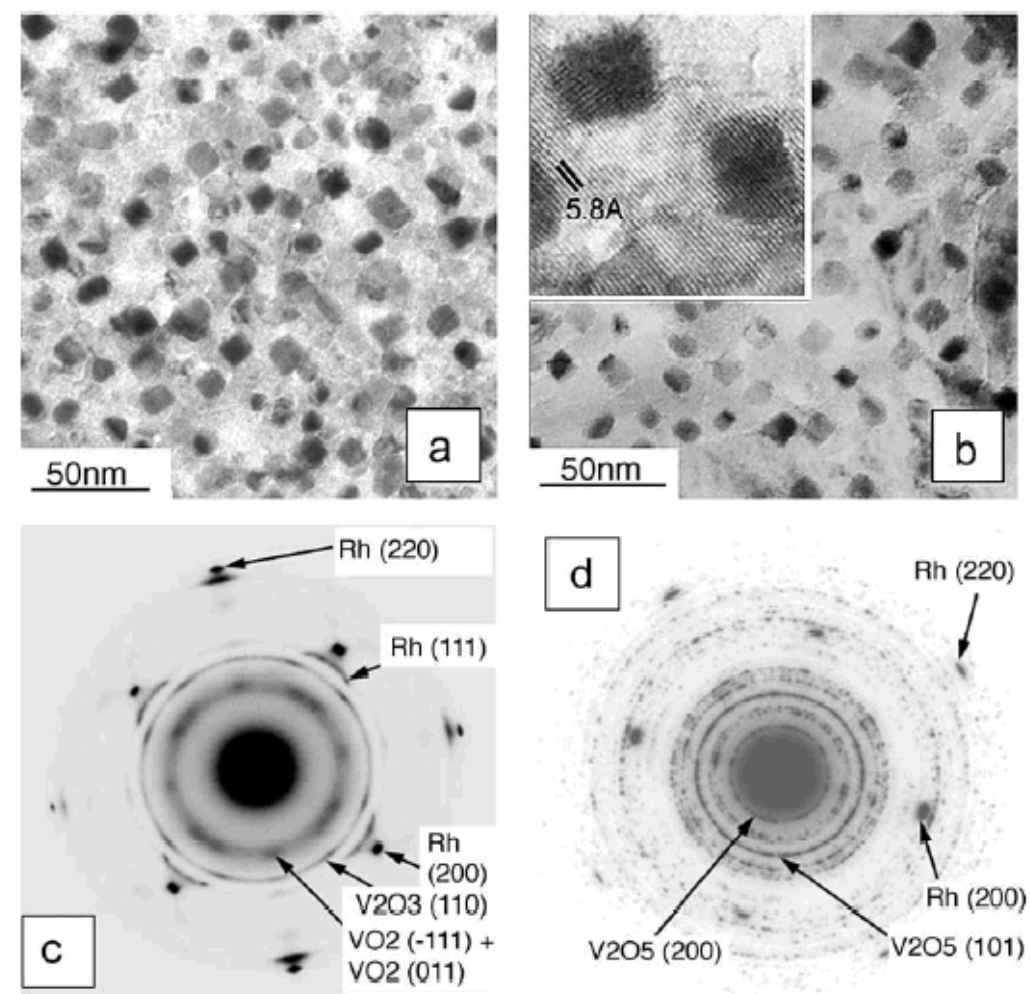

Fig. 9. $\mathrm{Rh} / \mathrm{V}_{2} \mathrm{O}_{3}$ film after oxidation at $573 \mathrm{~K}$ (a) and $673 \mathrm{~K}$ (b). The insert in (b) shows $\mathrm{V}_{2} \mathrm{O}_{5}$ (200) lattice fringes. SAED patterns are shown in (c) and (d).

pattern (Fig. 10f and Table 3) which can be assigned to the vanadium suboxides $\mathrm{VO}$ and $\mathrm{V}_{2} \mathrm{O}$ and to the alloy $\mathrm{Rh}_{5} \mathrm{~V}_{3}$, but at this temperature other $\mathrm{Rh}-\mathrm{V}$ alloys, particularly
$\mathrm{Rh}_{3} \mathrm{~V}$, cannot be excluded. Since metallic $\mathrm{Rh}$ was not detected it must be concluded that a treatment in 1 bar hydrogen at $673 \mathrm{~K}$ for $1 \mathrm{~h}$ is sufficient to complete the
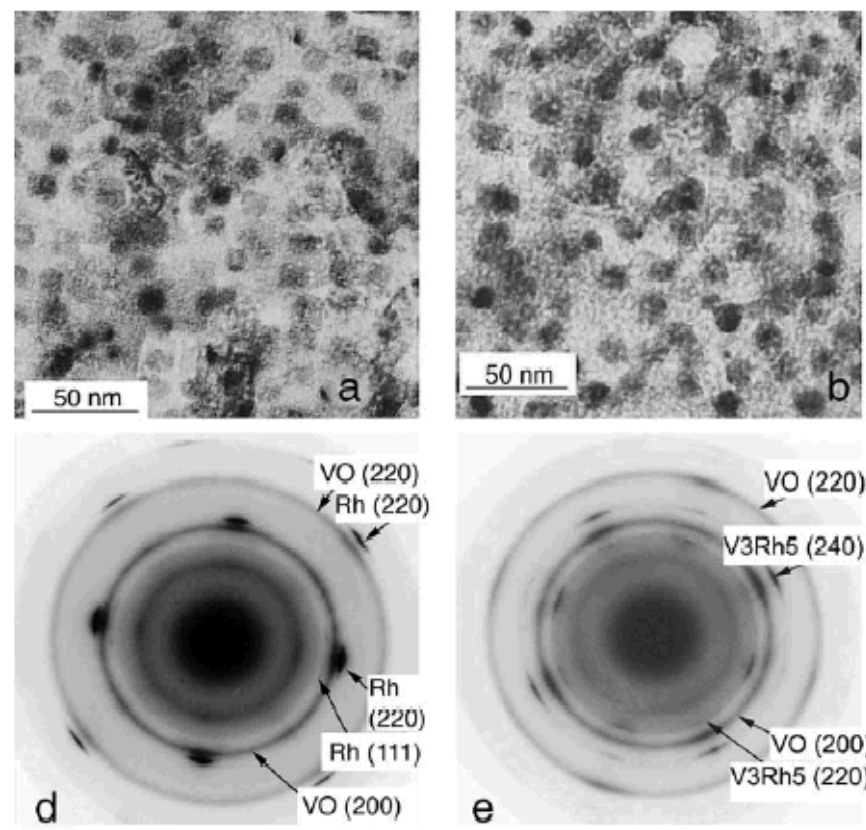

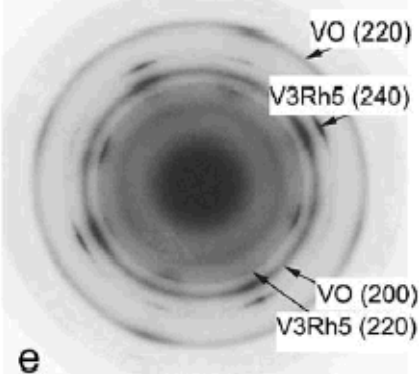

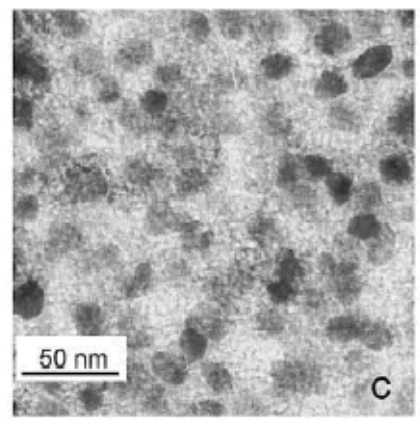

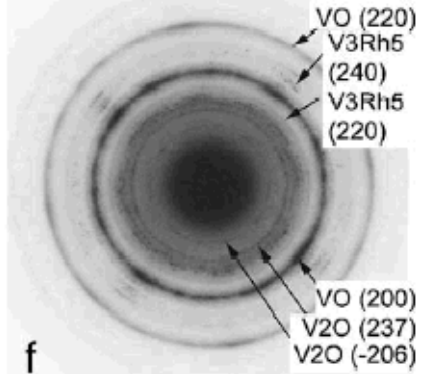

Fig. 10. Rh/ $\mathrm{V}_{2} \mathrm{O}_{3}$ film after oxidation at $673 \mathrm{~K}$ followed by reduction in 1 bar hydrogen at $473 \mathrm{~K}$ (a), $573 \mathrm{~K}$ (b) and $673 \mathrm{~K}$ (c). Corresponding SAED patterns in $(\mathrm{d}-\mathrm{f})$. 
Table 3

Interplanar distances $\mathrm{d}_{\mathrm{hk} 1}[\hat{\mathrm{A}}]$ measured on $\mathrm{Rh} / \mathrm{VO}_{\mathrm{x}}$ after reduction at 573 and $673 \mathrm{~K}$, and possible correlation to cubic $\mathrm{VO}$, monoclinic $\mathrm{V}_{2} \mathrm{O}, \mathrm{VO} / \mathrm{V}_{2} \mathrm{O}$ with unknown crystal structure (ui) [15], cubic $\mathrm{VRh}_{3}$ and orthorhombic $\mathrm{V}_{3} \mathrm{Rh}_{5}$

\begin{tabular}{|c|c|c|c|c|c|}
\hline \multicolumn{3}{|c|}{$\underline{\mathrm{Rh}} / \mathrm{VO}_{x}$ after reduction at $573 \mathrm{~K}$} & \multicolumn{3}{|c|}{$\mathrm{Rh} / \mathrm{VO}_{x}$ after reduction at $673 \mathrm{~K}$} \\
\hline \multicolumn{3}{|c|}{ Assignment } & \multicolumn{3}{|c|}{ Assignment } \\
\hline$d(\mathrm{hkl})_{\exp }$ & Lattice plane & $d(\mathrm{hkl})_{\text {dheor }}$ & $d(\mathrm{hkl})_{\exp }$ & Lattice plane & $\mathrm{d} d(\mathrm{hkl})_{\text {theor }}$ \\
\hline 2.31 & $\mathrm{~V}_{3} \mathrm{Rh}_{5}(220)$ & {$[2.34]$} & 3.94 & $\mathrm{~V}_{2} \mathrm{O}(-206)$ & [3.88] \\
\hline 2.03 & VO $(200)$ & {$[2.03]$} & 3.05 & $\mathrm{~V}_{2} \mathrm{O}(237)$ & {$[3.02]$} \\
\hline \multirow[t]{4}{*}{1.76} & $\mathrm{~V}_{3} \mathrm{Rh}_{5}(240)$ & {$[1.76]$} & 2.76 & $\mathrm{~V}_{2} \mathrm{O}(271)$ & [2.79] \\
\hline & & & & $\mathrm{V}_{3} \mathrm{Rh}_{5}(200)$ & {$[2.71]$} \\
\hline & & & & $\mathrm{V}_{2} \mathrm{O}$, VO ui & {$[2.70]$} \\
\hline & & & & & {$[2.71]$} \\
\hline \multirow[t]{19}{*}{1.42} & VO $(220)$ & {$[1.43]$} & 2.56 & $\mathrm{~V}_{2} \mathrm{O}(464)$ & {$[2.58]$} \\
\hline & & & 2.49 & $\mathrm{~V}_{2} \mathrm{O}$, VO ui & {$[2.47]$} \\
\hline & & & & & {$[2.48]$} \\
\hline & & & 2.34 & $\mathrm{~V}_{3} \mathrm{Rh}_{5}(220)$ & {$[2.34]$} \\
\hline & & & 2.14 & $\mathrm{~V}_{3} \mathrm{Rh}_{5}(002)$ & [2.16] \\
\hline & & & & $\mathrm{VRh}_{3}(111)$ & {$[2.17]$} \\
\hline & & & & $\mathrm{V}_{2} \mathrm{O}$, $\mathrm{VO}$ ui & [2.16] \\
\hline & & & & & {$[2.18]$} \\
\hline & & & 2.03 & VO $(200)$ & {$[2.03]$} \\
\hline & & & 1.93 & $\mathrm{~V}_{3} \mathrm{Rh}_{5}$ ui & {$[1.92]$} \\
\hline & & & 1.89 & $\mathrm{~V}_{2} \mathrm{O}(578)$ & {$[1.89]$} \\
\hline & & & & $\mathrm{VRh}_{3}(200)$ & [1.89] \\
\hline & & & 1.76 & $\mathrm{~V}_{3} \mathrm{Rh}_{5}(240)$ & {$[1.76]$} \\
\hline & & & 1.70 & $\mathrm{~V}_{3} \mathrm{Rh}_{5}(202)$ & [1.69] \\
\hline & & & & $\mathrm{V}_{2} \mathrm{O}$, VO ui & {$[1.68]$} \\
\hline & & & & & {$[1.69]$} \\
\hline & & & 1.64 & $\mathrm{~V}_{3} \mathrm{Rh}_{5}(241)$ & [1.63] \\
\hline & & & & $\mathrm{V}_{2} \mathrm{O}\left(\begin{array}{lll}3 & 7 & 12\end{array}\right)$ & {$[1.65]$} \\
\hline & & & 1.43 & VO (220) & {$[1.43]$} \\
\hline
\end{tabular}

alloy formation on this particular $\mathrm{Rh} / \mathrm{VO}_{\mathrm{x}}$ system with $\mathrm{Rh}$ particles of $10-15 \mathrm{~nm}$ in size. Larger Rh particles will require a significantly higher reduction temperature (up to $873 \mathrm{~K})$ to be transformed into the alloy state.

If we compare this behaviour to that of a corresponding inverse catalyst - $\mathrm{a} \mathrm{VO}_{\mathrm{x}}$ submonolayer on a $\mathrm{Rh}$ foil $[7,8]$ - we remember that a reduction in 100 mbar hydrogen induces the formation of the subsurface alloy at $773 \mathrm{~K}$ and above, which is in good qualitative agreement with our present observations. It is, however, of interest to note that a reduction at $573-623 \mathrm{~K}$ leads the present system into an intermediate state with a thin alloy phase $\left(\mathrm{Rh}_{5} \mathrm{~V}_{3}\right)$ in topotactic relation to the $\mathrm{Rh}$ particles. This state may be a starting point for an investigation of catalytic properties which may be comparable to those of the subsurface $\mathrm{Rh} / \mathrm{V}$ alloy on the inverse $\mathrm{Rh}$ catalyst.

The resulting $\mathrm{Rh} / \mathrm{V}$ alloys are surprisingly stable in air and oxygen. They obviously survive the transfer to the electron microscope, and an oxidation at 1 bar above 573 $\mathrm{K}$ is necessary to destroy the alloy structure completely.

\section{Conclusions}

The structure and composition of the pure vanadium film depend on the deposition rate (in $10^{-4}$ mbar oxygen) and on the temperature of the $\mathrm{NaCl}$ template. Low deposition rates and high substrate temperatures favour the generation of a pure $\mathrm{V}_{2} \mathrm{O}_{3}$ phase partly in epitaxial relation to $\mathrm{NaCl}(001)$. A treatment in 1 bar $\mathrm{O}_{2}$ between 300 and $573 \mathrm{~K}$ converts the supporting oxide into mixed $\mathrm{V}_{2} \mathrm{O}_{3}, \mathrm{VO}_{2}$ and $\mathrm{V}_{2} \mathrm{O}_{5}$ phases. Oxidation at $673 \mathrm{~K}$ induces a complete reconstruction into a uniform $\mathrm{V}_{2} \mathrm{O}_{5}$ phase. Reduction of the bare $\mathrm{V}_{2} \mathrm{O}_{5}$ film in 1 bar hydrogen yields cubic VO at $673 \mathrm{~K}$.

The $\mathrm{Rh} / \mathrm{VO}_{\mathrm{x}}$ film was subjected to consecutive heat treatments in 1 bar oxygen and in 1 bar hydrogen up to 673 $\mathrm{K}$. The as-grown $\mathrm{Rh} /$ vanadia catalyst is characterized by partial epitaxial relationships between the Rh particles and the $\mathrm{VO} / \mathrm{V}_{2} \mathrm{O}_{3}$ support. A 1 bar oxygen treatment transforms the support into $\mathrm{V}_{2} \mathrm{O}_{5}$ at $673 \mathrm{~K}$ and the $\mathrm{Rh}$ particles into $\beta$ $\mathrm{Rh}_{2} \mathrm{O}_{3}$ at $723 \mathrm{~K}$. A reduction of the $\mathrm{Rh} / \mathrm{V}_{2} \mathrm{O}_{5}$ film at $473 \mathrm{~K}$ produces VO. Finally, the reduction of vanadia-supported $\mathrm{Rh}$ particles at and above $573 \mathrm{~K}$ results in the formation of $\mathrm{Rh} / \mathrm{V}$ alloy structures with $\mathrm{Rh}_{5} \mathrm{~V}_{3}$ as the most prominent one. This finding agrees at least qualitatively with the formation of subsurface alloys observed on single crystal and polycrystalline surfaces and offers a perspective for future applications in catalysis.

\section{Acknowledgement}

We thank the Austrian Science Fund for support under Project S 8105 .

\section{References}

[1] M. Ichikawa, K. Shikakura, in: T. Seijama, K. Tanabe (Eds.), Proceedings of the 7th Int. Congress on Catalysis, Kondansha, Tokyo, 1980 , p. 1468.

[2] J. Kowalski, G. van der Lee, V. Ponec, Appl. Catal. 19 (1985) 423.

[3] S.J. Tauster, S.C. Fung, R.L. Garten, J. Am. Chem. Soc. 100 (1978) 170.

[4] H.J. Luo, A.G.T.M. Bastein, A.A.J.P. Mulder, V. Ponec, Appl. Catal. 38 (1988) 241

[5] A.B. Boffa, C. Lin, A.T. Bell, G.A. Somorjai, Catal. Lett. 27 (1994) 243.

[6] T. Hartmann, H. Knözinger, Z. Phys. Chem. 197 (1996) 113.

[7] W. Reichl, K. Hayek, J. Catal. 208 (2002) 422.

[8] W. Reichl, K. Hayek, Surf. Sci. 537 (2003) 247.

[9] W. Reichl, K. Hayek, J. Catal. 222 (2004) 53.

[10] K. Hayek, B. Jenewein, B. Klötzer, W. Reichl, Top. Catal. 13 (2000) 55.

[11] G. Rupprechter, K. Hayek, L. Rendón, M.J. Yacamán, Thin Solid Films 260 (1995) 148.

[12] Powder Diffraction File, International Center for Diffraction Data 1994, PDF Series 2 Sets 1-47.

[13] X.W. Lin, Y.Y. Wang, V.P. Dravid, P.M. Michalakos, M.C. Kung, Phys. Rev., B 47 (1993) 3477.

[14] D.S. Su, R. Schlögl, Catal. Lett. 83 (2002) 115.

[15] R.F. Egerton, Electron energy loss spectroscopy in the electron microscope, Plenum, New York, 1986.

[16] G. Rupprechter, K. Hayek, H. Hofineister, J. Catal. 173 (1998) 409. 